\title{
Activation of Nodl and Nod2 Induces Innate Immune Responses of Prostate Epithelial Cells
}

\author{
Min-Jung Kang, ${ }^{1,2}$ Sook-Kyoung Heo, ${ }^{1}$ Eun-Jung Song, ${ }^{1}$ Dong-Jae Kim, ${ }^{3}$ Seung-Yun Han, \\ Ju-Hee Han, ${ }^{5}$ Bo-Yeon Kim, ${ }^{2}$ and Jong-Hwan Park ${ }^{1,2 *}$ \\ 'Department of Biochemistry, College of Medicine, Konyang University, Daejeon, Korea \\ ${ }^{2}$ World Class Institute, Korea Research Institute of Bioscience and Biotechnology, Ochang-Eup, Cheongwon-Gun, \\ Choongbuk, Korea \\ ${ }^{3}$ Department of Pathology, University of Michigan Medical School, Ann Arbor, Michigan \\ ${ }^{4}$ Department of Anatomy, College of Medicine, Konyang University, Daejeon, Korea \\ ${ }^{5}$ Laboratory Animal Medicine, College of Veterinary Medicine, Seoul National University, Seoul, Korea
}

\begin{abstract}
BACKGROUND. Nod1 and Nod2 are cytosolic receptors which are responsible for sensing bacterial peptidoglycan derivatives. In this study, we determined whether Nod1 and Nod2 are involved in the innate immune responses of prostate epithelial cells.

METHODS. The expression of Nod1 and Nod2 was examined by RT-PCR and immunohistochemistry. ELISA was performed to determine the production of cytokines/chemokines. Activation of NF- $\mathrm{kB}$ and MAPK was examined using western blot analysis.

RESULTS. The Nod1 gene was distinctly expressed in all tested cells including DU145, PC3, and TRAMP-C2 cells, whereas Nod2 expression was weak. Both Nod1 and Nod2 proteins were expressed in normal mouse prostate epithelia with difference of expression levels. TriDAP (Nod1 agonist), but not MDP (Nod2), increased the production of IL-8 (or KC) and IL-6 in prostate epithelial cells. Tri-DAP and MDP could upregulate the gene expression of COX-2 and activate NF- $\mathrm{KB}$ and MAPK. In addition, Tri-DAP and MDP synergized with TLR agonists to induce the production of IL-8/KC or IL-6 in PC3 and TRAMP-C2 cells. We finally showed that Nod1 and Nod2 were also expressed in a wide range of prostate lesions including prostate intraepithelial neoplasm (PIN), phyllodes-like tumor, and adenocarcinoma in TRAMP (transgenic adenocarcinoma of the mouse prostate) mice, even though the expression level of Nod1 and Nod2 was different.

CONCLUSION. These results indicate that Nod1 and Nod2 may play important roles in the innate immune response of prostate epithelial cells and the development and progression of prostate cancer. Prostate 72:1351-1358, 2012. (C) 2012 Wiley Periodicals, Inc.
\end{abstract}

KEY WORDS: Nod1; Nod2; innate immune response; prostate epithelial cells; cyclooxygenase-2

\section{INTRODUCTION}

The detection of microbial products by pattern recognition receptors (PRRs) such as Toll-like receptors (TLRs) and Nod-like receptors (NLRs) initiates innate immune responses, which play a critical role in host defense against invading pathogens. TLRs recognize conserved microbial molecules including lipoproteins, LPS, flagellin, and nucleic acids at the cell surface or endosomal membrane [1]. In addition, TLRs also sense various endogenous ligands including heat shock proteins (Hsp), fibronectin, and high mobility
Grant sponsor: Ministry of Education, Science and Technology of Korea (MEST); Grant number: 2010-0002626 and 2009-002.

Conflicts of interest: None.

*Correspondence to: Jong-Hwan Park, Department of Biochemistry, College of Medicine, Konyang University 28, Wonangmaeul-1 Rd, Seo-gu, Daejeon 302-711, Korea. E-mail: jonpark@konyang.ac.kr Received 2 September 2011; Accepted 12 December 2011 DOI 10.1002/pros. 22483

Published online 6 January 2012 in Wiley Online Library (wileyonlinelibrary.com). 
group box-1 (HMGB-1) and are involved in various human diseases [2-3].

NLRs are another family of PRRs that mediate the cytosolic recognition of microbial molecules. NLRs consist of an $\mathrm{N}$-terminal effector domain including a caspase recruitment domain (CARD) or a pyrin $\mathrm{N}$ terminal homology domain (PYD); a central nucleotide-binding oligomerization domain (Nod); and a putative C-terminal pathogen-sensing domain consisting of leucine-rich repeats (LRR) [4]. There are 23 NLR family members in humans, and at least 34 genes in mice [5]. NLRs are expressed in nonimmune cells including epithelial cells and mesothelial cells and in immune cells [6-7]. The first identified NLRs were Nod1 and Nod2, which recognize meso-diaminopimelic acid (meso-DAP) and muramyl dipeptide (MDP), the derivatives of bacterial peptidoglycans, respectively [4]. After recognition, Nod1 and Nod2 associate with a serine/threonine kinase, RICK/Rip2, via a CARD-CARD interaction, subsequently leading to $\mathrm{NF}-\kappa \mathrm{B}$ activation and the production of inflammatory mediators [8]. In addition, Nod2 can recognize viral ssRNA and initiate innate immune antiviral responses by producing IFN- $\beta$ through IRF3 activation [9].

The prostate is associated with various pathological conditions such as chronic inflammation, benign hyperplasia, and cancer. Prostatitis is the most common urologic syndrome in men younger than 50 years of age [10] and affects 11-16\% of American men [11-12]. Although the majority prostatitis cases are not associated with bacterial infection, a small portion of prostatitis cases are due to acute or chronic bacterial infection [13]. According to the NIH classification of prostatitis, Class I and II cases are associated with bacterial infection [14-15]. Class I corresponds to acute bacterial prostatitis with a uropathogen, often with systemic symptoms of fever, chills, and hypotension. Class II corresponds to chronic bacterial prostatitis. Gram-negative bacteria such as E. coli, Klebsiella, and Pseudomonas are predominantly responsible for chronic bacterial prostatitis [13,16]. Host immune responses against microbial infection are closely associated with tumor development and progression as well as inflammation in the prostate. Therefore, it is of therapeutic value to understand the mechanisms responsible for the host immune response in the prostate. Although several studies have revealed the involvement of TLRs in the immune responses of prostate epithelial cells [17-19], little is known about whether Nod1 and Nod2 contribute to the innate immune responses of prostate epithelial cells. In this study, we examined the expression and immunological function of Nod1 and Nod2 in human and mouse prostate epithelial cells and tissues.

\section{MATERIALS ANDMETHODS}

\section{Cell Culture and Reagents}

The DU145, PC3 (human origin), and TRAMP-C2 (mouse origin) prostate epithelial cells lines were purchased from ATCC (Rockville, MD). DU145 and PC3 cells were incubated in RPMI medium containing 10\% fetal bovine serum (FBS) and $1 \times$ penicillin/streptomycin at $37^{\circ} \mathrm{C}$ in a $5 \% \mathrm{CO}_{2}$ atmosphere. TRAMP-C2 cells were incubated in DMEM medium containing $10 \%$ FBS, $1 \times$ penicillin/streptomycin, $5 \mu \mathrm{g} / \mathrm{ml}$ bovine insulin, $10 \mathrm{nM}$ dehydroisoandrosterone, and 5\% $\mathrm{Nu}-$ Serum IV at $37^{\circ} \mathrm{C}$ in a $5 \% \mathrm{CO}_{2}$ atmosphere. TriDAP, ultrapure LPS from E. coli O111:B4, and $\mathrm{Pam}_{3} \mathrm{CSK}_{4}$ were purchased from InvivoGen (San Diego, CA). MDP [Ac-(6-O-stearoyl)-muramyl-Ala-DGlu- $\mathrm{NH}_{2}$ ] was purchased from Bachem (Torrance, CA). Mouse bone marrow derived macrophages (BMDMs) were prepared as previously described [20].

\section{Animals}

Six weeks old male C57BL/ 6 mice were obtained from Orient Bio (Seongnam, Kyounggi-do, Korea) and used for immunohistochemistry on normal mouse prostate. As mouse prostate tumor model, TRAMP (transgenic adenocarcinoma of the mouse prostate) mice were purchased from The Jackson Laboratories (Bar Harbor, ME). TRAMP hemizygote mice (female) were mated with WT mice on C57BL $/ 6$ background. Animal experiment was approved and followed by the regulations of the Institutional Animal Care and Use Committee in Konyang University.

\section{RNA Extraction and ReverseTranscription- Polymerase Chain Reaction (RT-PCR)}

Total RNA was extracted from each cell using easy-BLUE (Intron biotechnology, Daejeon, KOREA) according to the manufacturer's instruction. One microgram of total RNA was reverse transcribed into cDNA, and PCR was performed using the Power cDNA Synthesis Kit (Intron biotechnology) and Onestep RT-PCR with AccuPower ${ }^{\circledR}$ HotStart PCR PreMix (Bioneer, Daejeon, Korea). The following primer sets were used.

$\begin{array}{ll}\text { human Nod1, } & \text { F: 5'-CCACTTCACAGCTGGAGACA-3' } \\ & \text { R: 5'-TGAGTGGAAGCAGCATTTTG-3' } \\ \text { human Nod2, } & \text { F: 5'-GAATGTTGGGCACCTCAAGT-3' } \\ & \text { R: 5'CAAGGAGCTTAGCCATGGAG-3' } \\ \text { human GAPDH, } & \text { F: 5'-GTCGGAGTCAACGGATT-3' } \\ & \text { R: 5'-AAGCTTCCCGTCTCAG-3' } \\ & \text { F: 5'-TTCAAATGAGATTGTGGGAA } \\ & \text { AAT-3' }\end{array}$


human

cyclooxygenase

(Cox)-2,

\section{R: 5'-AGATCATCTCTGCCTGAGT ATCTT-3'}

mouse Nod1, F: 5'-AGCTGCAGCCTTGCTTTAGCC-3'

R: 5'-TCAGCCATAAATGCCGTAGCG-3'

mouse Nod2,

F: 5'-CCGAAGCCCTAGCACTGATGC-3'

R: 5'-CAACCATCACGACTCCTCGGG-3'

mouse $\beta$-actin, F: $5^{\prime}$-ATGGATGACGATATCGCT $-3^{\prime}$

R: 5'-ATGAGGTAGTCTGTCAGGT -3'

mouse GAPDH, F: 5' - GTGGAGATTGTTGCCATC

AACG -3'

R: 5' - CAGTGGATGCAGGGATGATG

TTCTG $-3^{\prime}$

The PCR conditions consisted of 1 cycle of $94^{\circ} \mathrm{C}$ for $5 \mathrm{~min} ; 35 \mathrm{cycles}$ of $94^{\circ} \mathrm{C}$ for $30 \mathrm{sec}, 56-60^{\circ} \mathrm{C}$ for $30 \mathrm{sec}$, and $72^{\circ} \mathrm{C}$ for $30 \mathrm{sec}$; and 1 cycle of $72^{\circ} \mathrm{C}$ for $10 \mathrm{~min}$. PCR products were then electrophoresed on a $1.5 \%$ agarose gel and visualized using a gel documentation system.

\section{Immunohistochemistry}

Urogenital tissues including urinary bladder, seminal vesicle, and prostate were removed, fixed in $10 \%$ formalin over $24 \mathrm{hr}$, and processed in standard alcohol-xylene series. The tissues were embedded in paraffin and $3 \mu \mathrm{m}$ sections were prepared. They were treated with $0.3 \%$ hydrogen peroxide $\left(\mathrm{H}_{2} \mathrm{O}_{2}\right)$ in PBS for $30 \mathrm{~min}$ and $10 \%$ normal goat serum in PBS for 30 min for blocking. Subsequently, the sections were incubated with diluted rabbit isotype IgG, anti-Nod1, and anti-Nod2 (1:200; Imgenex, San Diego, CA) overnight at room temperature and subsequently exposed to biotinylated goat anti-rabbit IgG and streptavidin peroxidase complex (Vector, Burlingame, CA). Then, the sections were visualized with 3,3'-diaminobenzidine in $0.1 \mathrm{M}$ Tris- $\mathrm{HCl}$ buffer and counterstained with methyl green (Sigma, St. Louis, MO).

\section{Measurement of IL- 6 and IL-8/KC}

The cells were treated with the indicated doses of Tri-DAP and MDP for $24 \mathrm{hr}$, and the culture supernatant was collected. The concentrations of IL-6 and IL-8 (or KC for TRAMP -C2 cells) in the culture supernatants were determined using a commercial enzyme-linked immunosorbent assay (ELISA) kit (R\&D System).

\section{Western Blot Analysis}

The cells were lysed in buffer containing $1 \%$ NonidetP40 supplemented with a complete protease inhibitor cocktail (Roche) and $2 \mathrm{mM}$ dithiothreitol. Lysates were resolved by $10 \%$ SDS-PAGE, transferred to a polyvinylidene fluoride (PVDF) membrane, and immunoblotted with primary antibodies against IкB- $\alpha$, phospho-IкB- $\alpha$, p38, ERK, and JNK (Cell signaling, Beverly, MA). After immunoblotting with secondary antibodies, proteins were detected with an enhanced chemiluminescence (ECL) reagent (Intron Biotechnology).

\section{Statistical Analysis}

The differences among the mean values of the different groups were tested, and the values were expressed as the mean \pm SD. All of the statistical calculations were performed by one-way ANOVA followed by the Bonferroni post-hoc test for multigroup comparisons using GraphPad Prism version 5.01 (GraphPad Software, San Diego, CA). Values of $P<0.05$ were considered significant.

\section{RESULTS}

\section{Nodl and Nod2 are Expressed in Human and Mouse Prostate Epithelial Cells}

The gene expression of Nod1 and Nod2 was examined in both human and mouse prostate epithelial cells lines using RT-PCR. The Nod1 gene was markedly expressed in both DU145 and PC3 cells, whereas the gene expression of Nod2 was very weak in DU145 cells and undetectable in PC3 cells (Fig. 1A). However, stimulation with MDP, a Nod2specific agonist, augmented Nod2 expression in PC3

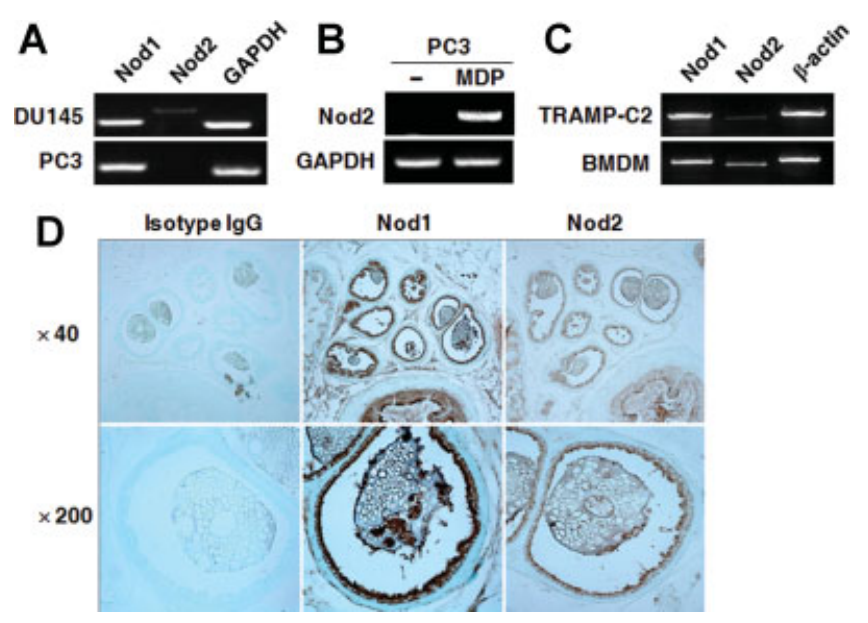

Fig. I. The gene and protein expression levels of Nodl and Nod2 in prostate epithelial cells and mouse prostate. The mRNA expression levels of Nodl, Nod2, and GAPDH $/ \beta$-actin were examined in human prostate epithelial cell lines (DUI45 and PC3) (A) and in a mouse prostate epithelial cell line (TRAMP-C2) and mouse BMDMs (C) by RT-PCR. In PC3 cells, Nod2 expression levels were determined by RT-PCR 2 hr after stimulation with or without MDP (B). The protein expression of Nodl and Nod2 was determined in mouse prostate by immunohistochemistry (D). 
cells (Fig. 1B). In addition, TRAMP-C2 mouse prostate epithelial cells also exhibited distinct gene expression of Nod1, the level of which was comparable to that in mouse BMDMs (Fig. 1C). The Nod2 gene was also detectable in TRAMP-C2 cells, but its expression level was relatively weak (Fig. 1C). Finally, we determined the protein expression of Nod1 and Nod2 in mouse prostate tissue. There was no signal in the isotypeIgG-treated section (Fig. 1D). However, both Nod1 and Nod2 expressions were detectable in the cytoplasm of prostate epithelia, but not stroma (Fig. 1D). In accordance with in vitro results, the intensity of Nod1 was much stronger than that of Nod2 (Fig. 1D).

\section{Nodl but not Nod2 Stimulation Enhanced IL- 8 (or KC) and IL- 6 Production in Prostate Epithelial Cells}

To determine whether stimulation of Nod1 and Nod2 leads to the production of proinflammatory cytokines/chemokines, the cells were treated with Tri-DAP (Nod1 agonist) and MDP (Nod2 agonist), and the amount of IL-8 (or its mouse homologue, KC) and IL-6 secreted into the culture supernatant was determined by ELISA. Tri-DAP, but not MDP, led to an increase in IL-8 production by PC 3 and DU145 cells (Fig. 2A,B). IL-6 production was also increased by Tri-DAP in PC3 cells in a dose-dependent manner (Fig. 2C). However, Tri-DAP did not enhance IL-6 production in DC145 cells (Fig. 2D). In TRAMP-C2 cells, the levels of KC and IL-6 were also upregulated by Tri-DAP in a dose-dependent manner (Fig. 2E,F). Similar to the result for PC3 and DU145 cells, MDP did not affect the production of KC or IL-6 in TRAMP-C2 cells (Fig. 2E,F).

\section{Tri-DAP and MDP as Well as LPS Induce the Gene Expression of Cyclooxygenase-2 in PC3 Cells}

We next sought to determine the effects of Nod1 and Nod2 activation on the gene expression of COX-2 in prostate epithelial cells. The results showed that Tri-DAP, MDP, and LPS could induce COX-2 mRNA expression in PC3 cells with different kinetics (Fig. 3). The gene expression of COX-2 induced by Tri-DAP was maximal $2 \mathrm{hr}$ after stimulation, whereas MDPinduced COX-2 expression was maximal $4 \mathrm{hr}$ poststimulation (Fig. 3). As a positive control, LPS also led to the induction of COX-2 expression (Fig. 3), albeit with slower kinetics compared to stimulation with Tri-DAP and MDP.

\section{Tri-DAP and MDP Lead to NF-KB and MAPK Activation in Prostate Epithelial Cells}

To determine whether Nod1 and Nod2 stimulation leads to NF-кB and MAPK activation in prostate
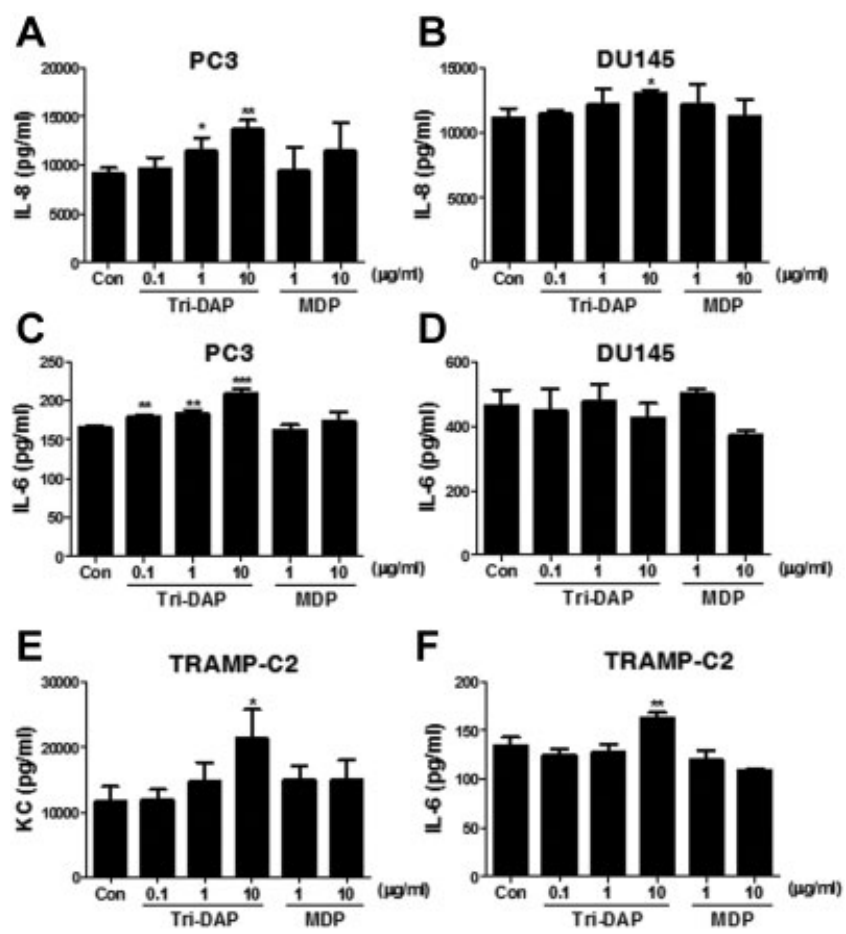

Fig. 2. The production of IL- 8 or its mouse homolog, KC, and IL- 6 by prostate epithelial cells in response to Tri-DAP and MDP.The cells $\left(2 \times 10^{4} /\right.$ well in a 48 -well plate $)$ were stimulated with the indicated doses of Tri-DAP or MDP for $24 \mathrm{hr}$, and the IL-8 (A and B)/KC (E) and IL-6 (C, D, and F) levels in the culture supernatant were determined using a commercial ELISA kit. The results are from one representative experiment of three independent experiments and are presented as the mean $\pm \mathrm{SD}$. ${ }^{*} P<0.05$, ${ }^{* *} P<0.01$, ${ }^{* * *}$ $P<0.001$.

epithelial cells, PC3 cells were treated with Tri-DAP or MDP, and extracts were prepared at different times after stimulation. Subsequently, immunoblotting was performed using antibodies that recognize activated forms of NF- $\mathrm{B}, \mathrm{p} 38$, JNK, and ERK. The results showed that Tri-DAP and MDP induced the phosphorylation of p38, ERK, JNK, and IкB- $\alpha$ (Fig. 4A,B), although the kinetics were different between Tri-DAP and MDP. At 15 min after stimulation, both Tri-DAP

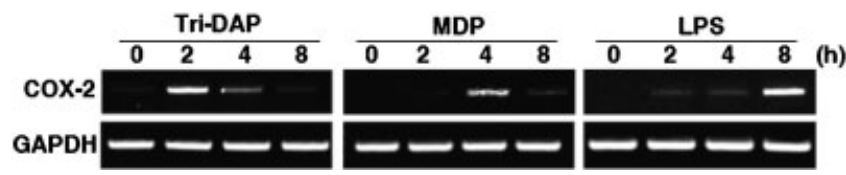

Fig. 3. COX-2 expression in PC3 cells in response to Nodl, Nod2, and TLR agonists. The cells were treated with Tri-DAP $(10 \mu \mathrm{g} / \mathrm{ml})$, MDP $(10 \mu \mathrm{g} / \mathrm{ml})$, or LPS $(I \mu \mathrm{g} / \mathrm{ml})$ for the indicated times, and COX-2 expression was determined by RT-PCR. The results are from one representative experiment of two independent experiments. 


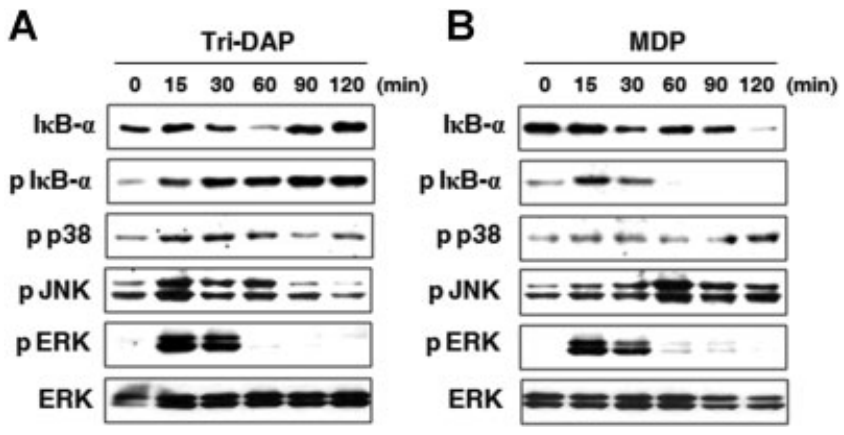

Fig. 4. NF- $K B$ and $M A P K$ activation in $P C 3$ cells in response to Tri-DAP and MDP. The cells were stimulated with $10 \mu \mathrm{g} / \mathrm{ml}$ of TriDAP (A) or MDP (B), and protein was extracted at the indicated time points. I $\mathrm{B}-\alpha$ degradation and the phosphorylation of $I_{\kappa} \mathrm{B}-\alpha$, P38, JNK, and ERK were examined by western blotting. A primary antibody against the all forms of ERK was used to confirm the loaded protein doses. The results are from one representative experiment of two independent experiments.

and MDP induced the phosphorylation of I $\mathrm{K} B-\alpha$. However, Tri-DAP induced prolonged ІкB- $\alpha$ phosphorylation compared to MDP stimulation. In addition, Tri-DAP induced optimal activation of p38 and JNK at $15 \mathrm{~min}$, whereas MDP induced at p38 and JNK activation at 120 and $60 \mathrm{~min}$ after stimulation, respectively (Fig. 4A,B). Similar levels of ERK phosphorylation were detected at 15 and $30 \mathrm{~min}$ after stimulation with either Tri-DAP or MDP (Fig. 4A,B).

\section{Nodl and Nod2 Synergy WithTLRs to Induce the Production IL- 6 and IL-8/KC in Prostate Epithelial Cells}

Dose-response experiments were performed to determine an appropriate dose of $\mathrm{Pam}_{3} \mathrm{CSK}_{4}$ (TLR2 agonist) and LPS (TLR4 agonist) to be used in the synergism experiment. The results revealed that $100 \mathrm{ng} / \mathrm{ml}$ of $\mathrm{Pam}_{3} \mathrm{CSK}_{4}$ and $1 \mu \mathrm{g} / \mathrm{ml}$ of LPS led to minor increases in IL-6 production in PC3 cells (data not shown), and these doses were used in the subsequent experiments. For the synergism experiment, PC3 cells were treated with the indicated agonist alone or in combination for $24 \mathrm{hr}$, and the IL-6 and IL8 production levels were measured using the culture supernatant. As shown in Figure 5A,B, the combination treatment with Tri-DAP and TLR agonists $\left(\mathrm{Pam}_{3} \mathrm{CSK}_{4}\right.$ or LPS) significantly enhanced IL-6 and IL-8 production in PC3 cells compared with treatment with the agonists alone. MDP also enhanced the IL-8 production induced by $\mathrm{Pam}_{3} \mathrm{CSK}_{4}$ or LPS in PC3 cells (Fig. 6C), although MDP itself did not induce the production of IL-8. In TRAMP-C2 cells, Tri-DAP and MDP also augmented the IL-6 production induced by $\mathrm{Pam}_{3} \mathrm{CSK}_{4}$ or LPS (Fig. 6D,E).

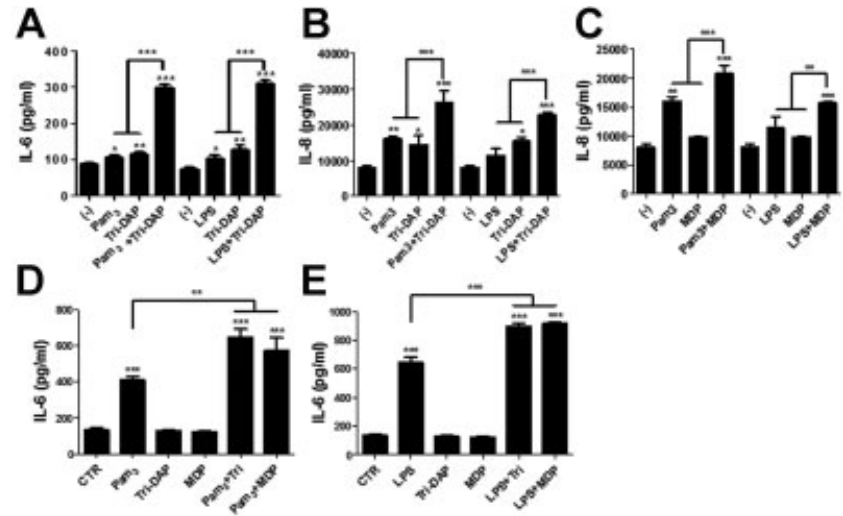

Fig. 5. Synergism of NLR and TLR agonists for IL- 6 and IL- 8 production in prostate epithelial cells. PC3 (A-C) and TRAMP-C2 (D and $\mathbf{E})$ cells were treated with the indicated agonist alone or their combination for $24 \mathrm{hr}$, and the IL-6 (A, D, and E) and IL- 8 (B and C) production levels were measured in the culture supernatant using ELISA.The results are from one representative experiment of three independent experiments and are presented as the mean $\pm \mathrm{SD}$. ${ }^{*} P<0.05,{ }^{* *} P<0.01$, ${ }^{* * *} P<0.001$.

\section{The Expression of Nodl and Nod2 in Prostate Tumor of Mice}

To determine the protein expression of Nod1 and Nod2 in mouse prostate tumor, immunohistochemistry was performed in the prostate tissue of TRAMP and age-matched WT mice (24 weeks old). Likely with Figure 1D, Nod1 and Nod2 were broadly expressed in the prostate epithelia of WT mice (Fig. 6A-D). A wide range of prostate lesions including low, moderate, and high-grade prostatic intraepithelial neoplasia (PIN), phyllodes-like tumor, and well-to-poorly differentiated adenocarcinoma were observed in TRAMP mice (data not shown). Nod1 and Nod2 were mainly expressed in glandular epithelial cells of high-grade PIN (E-H) or epithelia overlaying the stroma of the phyllodes-like tumor (Fig. 6I-L). Likely in normal mouse prostate, the intensity of Nod1 was much stronger than that of Nod2 (Fig. 6E-L). These phenomena were also observed in well-topoorly differentiated adenocarcinoma (data not shown). In glandular muscularis or the stroma of tumor, both Nod1 and Nod2 expressions were very weak (Fig. 6E-L). We also compared the gene expression of Nod1 and Nod2 between normal prostate (from age-matched WT mice) and prostatic tumor (from TRAMP mice). As shown in Figure 6M, mRNA of Nod1 in normal and tumor tissues of prostate was as strong as that in spleen and there was no difference of the intensity between two groups (normal tissues vs. tumor). Nod2 expression was very weak in both normal and tumor tissues, as compared with that in 

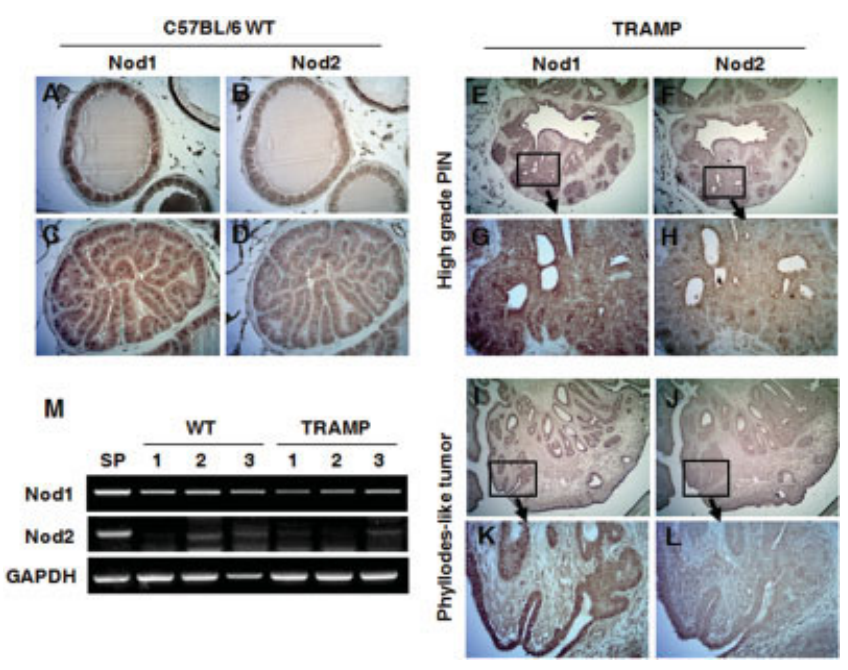

Fig. 6. (Original magnification) The gene and protein expression of Nodl and Nod2 in the prostate of WTand TRAMP mice. Immunohistochemistry was performed to determine the expression of Nodl and Nod2 in prostate of WT (age-matched) (A-D) and TRAMP (32 weeks old) (E-L) mice. G, H, K, and $\mathbf{L}$ were at $\times 100$ of magnification and others are at $\times 400$. RNA was extracted from the prostates of three mice in each group (WT and TRAMP; 32 weeks old) and the gene expression of Nodl, Nod2, and GAPDH was examined by RT-PCR $(\mathbf{M})$.

spleen (Fig. 6M). However, there seemed to be individual difference in the gene expression of Nod2 in mouse prostate. Nod2 expression in prostate was detectable in only two of three mice in each group, which prevents to compare the gene expression of Nod2 between the prostates of WT and TRAMP mice. To make a decision for the alteration of Nod2 expression on tumor progression of prostate, further study should be performed using the increasing number of mice.

\section{DISCUSSION}

Local epithelial cells are the first line of defense against microbial infection. In addition to providing a physical barrier, epithelial cells can initiate the host defense system by producing cytokines, chemokines, or antimicrobial peptides. Several TLRs have been found to contribute to immune responses in prostate epithelial cells. TLR4 regulates the expression of VEGF and TGF- $\beta 1$ in human prostate epithelial cells in response to LPS [17]. Mycoplasma hominis infection leads to IL-8 secretion in prostate epithelial cells through a TLR2-dependent mechanism [18]. In addition, TLR9 agonist CpG oligonucleotides (ODNs) promote inflammatory cytokines and upregulate the expression of COX-2 via NF-кB activation in prostate epithelial cells $[19,21]$. Although various epithelial cells in the skin, kidney, liver, stomach, and oral cavity functionally express Nod1 and Nod2 [7,22-25], the expression levels and function of Nod1 and Nod2 in prostate epithelial cells have not been clearly defined.

In this study, we first examined the gene expression of Nod1 and Nod2 in human (PC3 and DU145) and mouse (TRAMP-C2) prostate epithelial cells. Nod1 was distinctly expressed in both human and mouse prostate epithelial cell lines, whereas Nod2 expression was relatively weak in DU145 and TRAMP-C2 cells and undetectable in PC 3 cells. In addition, the protein of Nod1 and Nod2 was detectable in the cytoplasm of normal prostate epithelia in vivo, although the intensity of Nod1 was much stronger than that of Nod2. Nod1 mRNA has been reported to be strongly expressed in various types of epithelial cells $[7,22-23,26]$. However, the expression level of Nod2 was different between cell types. The mRNA and protein of Nod2 was markedly expressed in hepatocytes, oral epithelial cells, and renal tubular epithelial cells $[7,22-23]$ but was not expressed or was weakly expressed in intestinal epithelial cells [27]. In addition, Nod2 expression seems to be regulated by specific treatment. Treatment with bacterial flagellin (a TLR5 agonist), E. coli, and IL-1 $\beta$ could upregulate the gene expression of Nod2 in intestinal epithelial cells [27]. Furthermore, in the presence of histamine, MALP-2 (a TLR2 agonist), peptidoglycan, and $\beta$ glucan also enhanced Nod2 gene expression in keratinocytes [28]. In our study, the gene expression of Nod2 was also upregulated by MDP in PC 3 cells. It is likely that Nod1 is constitutively expressed, but Nod2 expression is inducible under specific conditions in prostate epithelial cells. In fact, in this study, there was no difference on the gene expression of Nod1 between normal prostate and prostatic tumor.

IL-8 is a proinflammatory CXC chemokine that has a key role in the recruitment and activation of neutrophils during inflammation. IL-6 is a multifunctional inflammatory cytokine that regulates chronic inflammation and can create a cellular microenvironment beneficial to cancer growth [29-30]. Prostate epithelial cells can produce IL-8 and IL-6 in response to bacterial infections with microbes such as Propionibacterium and Mycoplasma [18,31]. To determine whether Nod1 and Nod2 can promote the production of proinflammatory cytokines or chemokines in prostate epithelial cells, we examined IL-8/KC and IL-6 production in PC3, DU145, and TRAMP-C2 cells in response to TriDAP and MDP. Tri-DAP induced IL-6 and IL-8/KC production in all cell lines tested. However, MDP did not increase IL- 8 or IL-6 production in the cells. This result is in accordance with previous studies showing that MDP alone did not induce the production of proinflammatory cytokines or chemokines in most 
epithelial cells except those of intestinal origin $[7,26,32]$. Furthermore, in immune cells such as mouse BMDMs, MDP alone did not induce the production of cytokines such as IL- 6 and TNF- $\alpha$, even though MDP can induce NF- $\mathrm{BB}$ and MAPK activation [33]. In this study, MDP and Tri-DAP led to NF-кB and MAPK activation in PC3 cells, although with distinct kinetics. These findings suggest that Nod1 and Nod2 are expressed and may contribute to triggering immune response in prostate epithelial cells.

Cyclooxygenase is a key enzyme catalyzing the rate-limiting step of prostaglandin biosynthesis from arachidonic acid. There are three isoforms; COX-1 is a constitutive form, COX-2 is an inducible form, and COX-3 is present mainly in the brain and spinal cord [34]. Among these three proteins, COX-2 has been found to be correlated with prostate tumor growth and angiogenesis [35]. Moreover, COX-2 can directly promote cellular invasion in prostate cancer and the inhibition of COX-2 leads to decreased tumor cell invasiveness [36-37]. In this study, we revealed that the stimulation of Nod2 and Nod1 can induce the gene expression of COX-2 in PC3 cells. It remains to be clarified whether Nod1 and Nod2 are involved in aspects of tumor progression such as angiogenesis and invasiveness in prostate cancer.

Previous studies have shown that Nod1 and Nod2 have synergistic or additive effects with TLRs with respect to the production of cytokines and chemokines in immune cells and mesothelial cells $[6,33,38]$. These phenomena were also observed in epithelial cells. In oral epithelial cells, Nod1 and Nod2 agonists in combination with TLR agonists synergistically enhanced $\beta$-defensin 2 secretion [32]. Moreover, LPS pretreatment enhanced the activation of NF-кB, ERK, and JNK by MDP in hepatocytes [7]. Likewise, in this study, Nod1 and Nod2 agonists (Tri-DAP and MDP) synergized with TLR agonists $\left(\mathrm{Pam}_{3} \mathrm{CSK}_{4}\right.$ or LPS) to induce the production of IL-8 or IL-6 in PC3 and TRAMP-C2 cells. Our results indicate that Nod1 and Nod2 may cooperate with TLRs to elicit immune responses in prostate epithelial cells.

\section{CONCLUSION}

Inflammation is crucial for the etiology of prostate cancer. TLRs (other family of PRRs) activation is known to promote tumorigenic events such as cell proliferation, angiogenesis, metastasis, and immune suppression in various cancers including prostate cancer. Likely with TLRs, in the present study, we revealed that Nod1 and Nod2 are functionally expressed in human and mouse prostate epithelial cells and that the activation of those receptors can induce innate immune responses such as cytokine production, COX-2 expression, and the activation of NF-кB and MAPK. These findings indicate that Nod1 and Nod2 signaling may participate in the development and progression of prostate cancer, even though the gene expression of Nod1 and Nod2 was not changed in mouse prostatic tumors. Therefore, it is necessary to clarify whether Nod1 and Nod2 activation affects the cell proliferation, metastasis, or immune suppression in prostate cancers.

\section{ACKNOWLEDGMENTS}

This work was supported by a program (Grant No. 2010-0002626) for Basic Research in Science and Engineering and by the World Class Institute (WCI) program (Grant No. 2009-002) of the National Research Foundation of Korea (NRF) funded by the Ministry of Education, Science and Technology of Korea (MEST). The authors thank Dr. Michael H. Shaw (Department of Pathology, University of Michigan) for his kind advice.

\section{REFERENCES}

1. Takeuchi O, Akira S. Pattern recognition receptors and inflammation. Cell 2010;140(6):805-820.

2. Erridge C. Endogenous ligands of TLR2 and TL R4: Agonists or assistants? J Leukoc Biol 2010;87(6):989-999.

3. Garantziotis S, Hollingsworth JW, Zaas AK, Schwartz DA. The effect of toll-like receptors and toll-like receptor genetics in human disease. Annu Rev Med 2008;59:343-359.

4. Inohara N, Chamaillard M, McDonald C, Nunez G. NOD-LRR proteins: Role in host-microbial interactions and inflammatory disease. Annu Rev Biochem 2005;74:355-383.

5. Franchi L, Warner N, Viani K, Nunez G. Function of Nod-like receptors in microbial recognition and host defense. Immunol Rev 2009;227(1):106-128.

6. Park JH, Kim YG, Shaw M, Kanneganti TD, Fujimoto Y, Fukase K, Inohara N, Nunez G. Nod1/RICK and TLR signaling regulate chemokine and antimicrobial innate immune responses in mesothelial cells. J Immunol 2007;179(1):514-521.

7. Scott MJ, Chen C, Sun Q, Billiar TR. Hepatocytes express functional NOD1 and NOD2 receptors: A role for NOD1 in hepatocyte CC and CXC chemokine production. J Hepatol 2010; 53(4):693-701.

8. Hasegawa M, Fujimoto Y, Lucas PC, Nakano H, Fukase K, Nunez G, Inohara N. A critical role of RICK/RIP2 polyubiquitination in Nod-induced NF-kappaB activation. EMBO J 2008; 27(2):373-383.

9. Sabbah A, Chang TH, Harnack R, Frohlich V, Tominaga K, Dube $\mathrm{PH}$, Xiang $\mathrm{Y}$, Bose $\mathrm{S}$. Activation of innate immune antiviral responses by Nod2. Nat Immunol 2009;10(10):1073-1080.

10. Collins MM, Stafford RS, O'Leary MP, Barry MJ. How common is prostatitis? A national survey of physician visits. J Urol 1998; 159(4):1224-1228.

11. Roberts RO, Lieber MM, Rhodes T, Girman CJ, Bostwick DG, Jacobsen SJ. Prevalence of a physician-assigned diagnosis of prostatitis: The Olmsted County Study of Urinary Symptoms and Health Status Among Men. Urology 1998;51(4):578584 . 
12. Collins MM, Meigs JB, Barry MJ, Walker Corkery E, Giovannucci E, Kawachi I. Prevalence and correlates of prostatitis in the health professionals follow-up study cohort. J Urol 2002;167(3):1363-1366.

13. Domingue GJ Sr, Hellstrom WJ. Prostatitis. Clin Microbiol Rev 1998;11(4):604-613.

14. Krieger JN, Nyberg L Jr, Nickel JC. NIH consensus definition and classification of prostatitis. JAMA 1999;282(3):236-237.

15. Murphy AB, Macejko A, Taylor A, Nadler RB. Chronic prostatitis: Management strategies. Drugs 2009;69(1):71-84.

16. Rippere-Lampe KE, Lang $M$, Ceri H, Olson M, Lockman HA, $\mathrm{O}^{\prime}$ Brien AD. Cytotoxic necrotizing factor type 1-positive Escherichia coli causes increased inflammation and tissue damage to the prostate in a rat prostatitis model. Infect Immun 2001;69(10):6515-6519.

17. Pei $Z$, Lin D, Song $X, \mathrm{Li} H$, Yao H. TLR4 signaling promotes the expression of VEGF and TGFbeta1 in human prostate epithelial PC3 cells induced by lipopolysaccharide. Cell Immunol 2008;254(1):20-27.

18. Takeyama K, Mitsuzawa H, Shimizu T, Konishi M, Nishitani C, Sano H, Kunishima Y, Matsukawa M, Takahashi S, Shibata K, Tsukamoto T, Kuroki Y. Prostate cell lines secrete IL-8 in response to Mycoplasma hominis through Toll-like receptor 2-mediated mechanism. Prostate 2006;66(4):386-391.

19. Di JM, Pang J, Pu XY, Zhang $Y$, Liu XP, Fang YQ, Ruan XX, Gao X. Toll-like receptor 9 agonists promote IL-8 and TGFbeta1 production via activation of nuclear factor kappaB in PC-3 cells. Cancer Genet Cytogenet 2009;192(2):60-67.

20. Celada A, Gray PW, Rinderknecht E, Schreiber RD. Evidence for a gamma-interferon receptor that regulates macrophage tumoricidal activity. J Exp Med 1984;160(1):55-74.

21. Di JM, Pang J, Sun QP, Zhang Y, Fang YQ, Liu XP, Zhou JH, Ruan XX, Gao X. Toll-like receptor 9 agonists up-regulates the expression of cyclooxygenase-2 via activation of NF-kappaB in prostate cancer cells. Mol Biol Rep 2010;37(4):1849-1855.

22. Shigeoka AA, Kambo A, Mathison JC, King AJ, Hall WF, da Silva Correia J, Ulevitch RJ, McKay DB. Nod1 and nod2 are expressed in human and murine renal tubular epithelial cells and participate in renal ischemia reperfusion injury. J Immunol 2010;184(5):2297-2304.

23. Sugawara Y, Uehara A, Fujimoto Y, Kusumoto S, Fukase K, Shibata K, Sugawara S, Sasano T, Takada H. Toll-like receptors, NOD1, and NOD2 in oral epithelial cells. J Dent Res 2006; 85(6):524-529.

24. Viala J, Chaput C, Boneca IG, Cardona A, Girardin SE, Moran AP, Athman R, Memet S, Huerre MR, Coyle AJ, DiStefano PS, Sansonetti PJ, Labigne A, Bertin J, Philpott DJ, Ferrero RL. Nod1 responds to peptidoglycan delivered by the Helicobacter pylori cag pathogenicity island. Nat Immunol 2004;5(11):11661174.
25. Voss E, Wehkamp J, Wehkamp K, Stange EF, Schroder JM, Harder J. NOD2/CARD15 mediates induction of the antimicrobial peptide human beta-defensin-2. J Biol Chem 2006; 281(4):2005-2011.

26. Uehara A, Fujimoto Y, Fukase K, Takada H. Various human epithelial cells express functional Toll-like receptors, NOD1 and NOD2 to produce anti-microbial peptides, but not proinflammatory cytokines. Mol Immunol 2007;44(12):3100-3111.

27. Begue B, Dumant C, Bambou JC, Beaulieu JF, Chamaillard M, Hugot JP, Goulet O, Schmitz J, Philpott DJ, Cerf-Bensussan N, Ruemmele FM. Microbial induction of CARD15 expression in intestinal epithelial cells via toll-like receptor 5 triggers an antibacterial response loop. J Cell Physiol 2006;209(2):241-252.

28. Kobayashi M, Yoshiki R, Sakabe J, Kabashima K, Nakamura M, Tokura Y. Expression of toll-like receptor 2, NOD2 and dectin- 1 and stimulatory effects of their ligands and histamine in normal human keratinocytes. Br J Dermatol 2009;160(2):297304.

29. Lu H, Ouyang W, Huang C. Inflammation, a key event in cancer development. Mol Cancer Res 2006;4(4):221-233.

30. Hodge DR, Hurt EM, Farrar WL. The role of IL-6 and STAT3 in inflammation and cancer. Eur J Cancer 2005;41(16):2502-2512.

31. Drott JB, Alexeyev O, Bergstrom P, Elgh F, Olsson J. Propionibacterium acnes infection induces upregulation of inflammatory genes and cytokine secretion in prostate epithelial cells. BMC Microbiol 2010;10:126.

32. Uehara A, Takada H. Synergism between TLRs and NOD1/2 in oral epithelial cells. J Dent Res 2008;87(7):682-686.

33. Park JH, Kim YG, McDonald C, Kanneganti TD, Hasegawa M, Body-Malapel M, Inohara N, Nunez G. RICK/RIP2 mediates innate immune responses induced through Nod1 and Nod2 but not TLRs. J Immunol 2007;178(4):2380-2386.

34. Kis B, Snipes JA, Isse T, Nagy K, Busija DW. Putative cyclooxygenase-3 expression in rat brain cells. J Cereb Blood Flow Metab 2003;23(11):1287-1292.

35. Jain S, Chakraborty G, Raja R, Kale S, Kundu GC. Prostaglandin $\mathrm{E} 2$ regulates tumor angiogenesis in prostate cancer. Cancer Res 2008;68(19):7750-7759.

36. Attiga FA, Fernandez PM, Weeraratna AT, Manyak MJ, Patierno SR. Inhibitors of prostaglandin synthesis inhibit human prostate tumor cell invasiveness and reduce the release of matrix metalloproteinases. Cancer Res 2000;60(16):4629-4637.

37. Nithipatikom K, Isbell MA, Lindholm PF, Kajdacsy-Balla A, Kaul S, Campell WB. Requirement of cyclooxygenase-2 expression and prostaglandins for human prostate cancer cell invasion. Clin Exp Metastasis 2002;19(7):593-601.

38. van Heel DA, Ghosh S, Butler M, Hunt K, Foxwell BM, Mengin-Lecreulx D, Playford RJ. Synergistic enhancement of Toll-like receptor responses by NOD1 activation. Eur J Immunol 2005;35(8):2471-2476. 